\title{
PaturMata, a model to manage grassland under climate change
}

\author{
Pauline Dusseux • Yulong Zhao • Marie-Odile Cordier • \\ Thomas Corpetti $\cdot$ Luc Delaby • \\ Chantal Gascuel-Odoux • Laurence Hubert-Moy
}

Accepted: 29 January 2015 / Published online: 18 March 2015

C INRA and Springer-Verlag France 2015

\begin{abstract}
Agricultural intensification has greatly decreased grassland surface area in some regions, thus changing grassland management and modifying environmental and socioeconomic systems. Therefore, knowledge about grassland management practices in farming systems is needed for sustainable agriculture. In this context, the PaturMata model simulates grassland management at the farm scale. The PaturMata model simulates grassland dynamics and several factors such as farming practices, grass consumption, and fertilization. The model takes into account environmental and farming system parameters such as climate, field number, size, and location; livestock units; and conventional or organic agriculture. Here, we first ran the model under climatic conditions favorable to grass growth for four farms on an experimental site located in western France. Biophysical variables extracted from remote-sensing images were used to initialize PaturMata, whose predictions were compared to on-site surveys. We generated forecasting scenarios of
\end{abstract}

P. Dusseux $(\varangle) \cdot$ T. Corpetti $\cdot$ L. Hubert-Moy

LETG Rennes COSTEL Laboratory, Rennes 2 University,

UMR CNRS 6554, Place du Recteur Henri Le Moal,

35043 Rennes Cedex, France

e-mail: pauline.dusseux@gmail.com

Y. Zhao · M.-O. Cordier

Rennes 1 University, IRISA - UMR 6074,

Inria, 35000 Rennes, France

L. Delaby

INRA, UMR 1348 Production du Lait, 35590 Saint-Gilles, France

C. Gascuel-Odoux

INRA, UMR 1069 Sol Agro et hydrosystème Spatialisation,

35000 Rennes, France

C. Gascuel-Odoux

Agrocampus Ouest, 35000 Rennes, France the same farms under different climatic conditions. Results show that PaturMata predicts a $70 \%$ decrease in grass consumption, a $50 \%$ decrease in the number of annual grazing periods, and a $60 \%$ increase in the amount of conserved forage consumed, when conditions are unfavorable to grass growth. We conclude that the PaturMata model can help design farms and management strategies capable of coping with a wide range of conditions.

Keywords Grassland management strategies · Modeling of agricultural practices $\cdot$ Timed automata $\cdot$ Model checking $\cdot$ Remote sensing

\section{Introduction}

For several decades, scientific research has focused on understanding grassland systems, since changes in agricultural practices affect many aspects of the environment. Over the last century, major decrease in grassland surface area, associated with changes in their management, has occurred in many regions around the world (Peeters 2009; Poudevigne and Alard 1997). These land cover and land use changes, often associated with agricultural intensification, could have major impacts on environmental systems by increasing water and air pollution, soil degradation, or biodiversity loss (Lobell and Field 2007). Moreover, the functional role of grasslands changes with intensive agricultural practices such as an increase in fertilizer application or the number of mowing or grazing events. For example, the protective effects of grasslands in decreasing nitrate leaching and increasing carbon storage in soils decreases when grassland is converted into cropland or overgrazed (Vertès et al. 2007; Arrouays et al. 2001). These land cover and land use changes, along with the combined effect of climate 
change, may also have significant socio-economic impacts on stock and winter fodder (Batáry et al. 2007). For example, the temperature increase associated with decreased rainfall could significantly decrease grass production during the summer (Soussana and Lüscher 2007; Tubiello et al. 2007; Howden et al. 2007).

In this context, evaluating grassland status and estimating grassland production is a key issue for sustainable agriculture. This can be accomplished by using farm surveys; however, previous studies have had problems surveying large areas. A typical way to address this issue is to use remote-sensing data, whose spectral channels calculate vegetation indices and biophysical variables strongly correlated with vegetation growth, percentage of vegetation cover, crop height, and live biomass (Jacquemoud et al. 2009; Rondeaux et al. 1996). Classification of the resulting time series of biophysical variables can identify grassland farming practices (Dusseux et al. 2013).

Although remote sensing and ground observation can estimate changes in grassland states and thus identify farming practices, these data are not always available and are likely to be expensive when extended to large areas. Since observation alone cannot predict grassland states that depend on farm configuration (farm size, field number, farmer behavior, etc.), these states can be simulated using models that reproduce both grass growth and farmer behavior. A panel of techniques (models) was designed in the context of farming system dependence on a variety of factors (climate, markets, ecology, etc.), as reviewed by (Martin et al. 2013).

Among models designed for agro-ecosystem management, and more precisely for grassland simulation, the technique of (Martin et al. 2011; Cros et al. 1999) has the advantage of including several species (animals, grasses, etc.), but it does not explicitly represent grassland management (grazing, mowing, etc.). More specifically designed for grasslands, the Patur'IN model (Delaby et al. 2001) is a user-friendly interactive tool able to simulate grassland growth based on several physical parameters related to plants and climate. Although this tool is highly efficient to simulate grassland growth, it does not include management strategies. The model PaturMata addresses this issue: relying on Patur'IN, it gives the possibility to simulate management practices, while preserving process efficiency and user-friendly interactive capabilities (Zhao 2014). The model PaturMata was used in this study.

One major challenge in using models is evaluating their ability to reproduce farming systems. The main contribution of this paper is its analysis of the ability of PaturMata to simulate credible scenarios to understand and improve grassland management at the farm level. We used remote sensing data to configure PaturMata inputs with real physical values at a specific study site with available observations and knowledge about grassland practices. This enabled evaluation and validation of PaturMata's ability to generate plausible grassland changes. We used PaturMata to simulate scenarios under abnormal climatic conditions, which illustrated the importance of such models in the context of climate change.

Three types of grassland management practices during the growing season were investigated: grazing, mowing, and a combination of the two (mixed) (Fig. 1). Although vegetation states vary with land management, agricultural practices can be identified by analyzing biomass indices, crop height, or percentage of vegetation cover. Grazing decreases biomass and crop height (revealing soil if overgrazing), while mowing drastically and rapidly decreases biomass and crop height and leaves the soil background visible.

This paper is organized as follows: Section 2 includes materials and methods related to the study site, presents PaturMata, and introduces remote sensing data and validation criteria. Section 3 validates PaturMata with field survey data and illustrates its prospective power. Conclusions are given in the Section 4.

\section{Materials and methods}

\subsection{Study site}

The study site is the Yar watershed, located on the northern coast of Brittany in western France. This agricultural area is dominated by intensive farming oriented mainly toward cattle production. It experiences water pollution due to agricultural intensification. Though nitrate contents in rivers are around $30 \mathrm{mg} \mathrm{L}^{-1}$, i.e. , far below the $50 \mathrm{mg} \mathrm{L}^{-1}$ European threshold, the sensitivity of this coastal site to eutrophication has resulted in green tides for the past 40 years. The objective for water quality should be as low as $10 \mathrm{mg} \mathrm{L}^{-1}$ nitrate (Ménesguen and Piriou 1995). A research program was started to decrease nitrate emissions while ensuring sustainable farms and included close collaboration with local stakeholders, territory managers, and farmers. The program developed guidelines based on a set of simple indicators to promote an increase in the percentage of grassland in utilized agricultural area (UAA) (stocking rate per hectare grassland, $N$ input, and reduction of risky practices such as leaving soil bare and plowing up grassland) (Moreau et al. 2012; Moreau et al. 2013). A large percentage of the study area is covered by grasslands ( $60 \%$ of UAA) in a variety of organic or conventional systems that are dominated by dairy cattle production. Three main types of management occur during the growing season: grazing, mowing, and mixed. In western France, grasslands are usually grazed or grazed and mowed rather than only mowed. Field surveys were 
Fig. 1 In western France, grazing (left) and mowing (right) practices can be observed in grasslands during the growing period
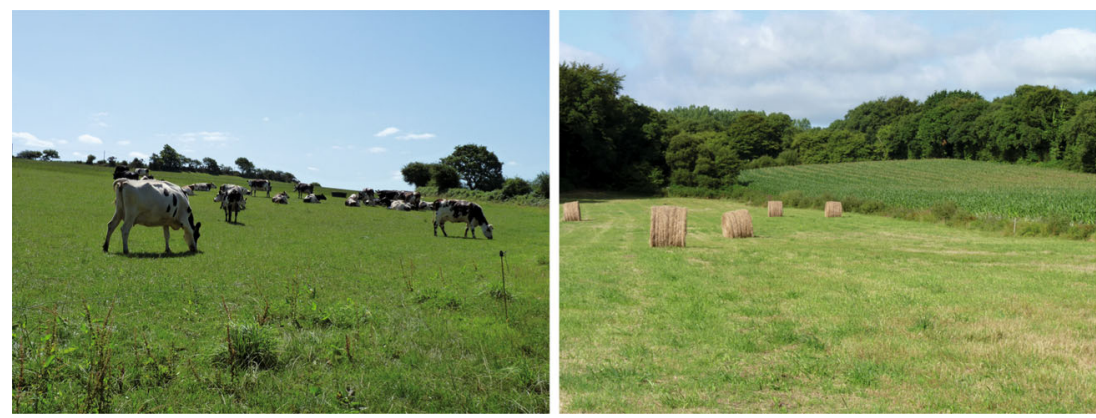

conducted on 4 of the 70 farms located in the study site to obtain information on grassland management practices. This information was used to validate PaturMata.

\subsection{Description of PaturMata}

The PaturMata model was designed mainly to study grasslands under different management strategies. It simulates grassland paddock growth and considers agricultural activities that directly influence grassland (cattle entrance and exit, grass mowing, and application of $N$ fertilizer) and management strategies related to these activities. These elements are represented in a hierarchy of model layers:

- The grassland layer, the biological part of the model, represents the rate of grass growth in each paddock and how quickly animals consume the grass;

- The execution layer models the agricultural activities in sub-models: cattle entrance and exit, grass mowing, and fertilizer application. These sub-models also contain rules for agricultural activities based on the state of the grassland layer. If these sub-models are asked to execute activities that violate the rules, they stop execution of the entire model;

- The controller layer models management strategies with controllers, which tell the execution layer when to perform actions;

- The central clock counts how many days have passed during the simulation, which ends when the simulation length has been reached.

In PaturMata, the models are described in a timed automaton form (Alur and Dill 1994). An automaton is a graphical representation where nodes correspond to states and edges correspond to changes of states triggered by events. The changes of states may be temporally constrained events, justifying then the timed automaton terminology. Model checking techniques are used to simulate the grazing model. Model checking techniques are dedicated to timed automata simulation. Given contextual data, they compute in a very efficient way the model output. In PaturMata, model checking techniques execute all sub-models and the entire model in timed automaton form. Execution of a grazing model as a timed automaton can be rapid due to the exceptional performance of existing model-checking tools. To simulate a specific farm, one needs to enter the following data:

- Physical characteristics of the farm: surface area, number of fields (Nb fields), livestock units (LSU), and percentage of fields whose distance from the homestead is $\leqslant 500 \mathrm{~m}$ (close), 500-1000 m (medium), and $\geqslant 1000 \mathrm{~m}$ (far);

- Amount of fertilizer applied;

- Grass height limits (minimum grass height to begin mowing, pasture height limits, height after mowing);

- Climatic conditions: favorable, unfavorable, or very unfavorable for grassland growth.

PaturMata randomly creates a set of farms (in practice, 10) that have these characteristics. It then generates a model of each farm in timed automaton form, executes it, and retrieves the output from the model checking tool (Alur and Dill 1994).

All tasks are embedded in a single software package, providing a user-friendly interface with which users can easily enter information about grazing, fertilizers, and climatic conditions. Details about PaturMata can be found in (Zhao 2014).

\subsection{Remote sensing data}

Remote sensing data were used to configure input data of PaturMata. Land cover maps at the field scale were derived from high-resolution satellite data (SPOT and Landsat images) using commercial software (ArcGIS, Ecognition). Information derived from remote sensing data about grasslands on each farm (total grassland area, number of grassland fields, percentage of grassland fields located in wetland areas, distance of each grassland field from the homestead) was used by PaturMata in simulations.

Characteristics describing the state of the vegetation were calculated after grasslands were extracted from remotesensing data by automatic classification tools (Dusseux et al. 2014). We focused on leaf area index (LAI), a key biophysical variable, derived from satellite images using the 
PROSAIL radiative-transfer model (Jacquemoud et al. 2009). LAI is correlated with grass height and density (Zhang and Guo 2008; Guo et al. 2000; Friedl et al. 1994). LAI estimated from remote-sensing images were used to estimate the grass height observed at the beginning of the simulation, the beginning and end of grazing, and the beginning of mowing. LAI was also used as an input for PaturMata simulations.

\subsection{Validation criteria}

Regular measurements and surveys were performed on the study site to determine key elements of agricultural practices on grasslands (beginning and end of grazing, number of grazing and mowing events during the season, etc.). The characteristics used to evaluate the correspondence between PaturMata predictions and observed data from remote sensing and on-site surveys were the following:

- $N_{\mathrm{G}}$, mean number of grazing periods per field each year;

- $N_{\mathrm{M}}$, mean number of mowing events per field each year;

- $T_{\mathrm{G}}, T_{\mathrm{M}}, T_{\mathrm{MM}}$; grassland management strategies for each field: grazing $\left(T_{\mathrm{G}}\right)$, mowing $\left(T_{\mathrm{M}}\right)$, or mixed $\left(T_{\mathrm{MM}}\right)$;

- GG, number of days between two grazing events;

- MM, number of days between two mowing events;

- GM, number of days between two successive grazing and mowing events;

- MG, number of days between two successive mowing and grazing events.

\subsection{Experimental design}

Remote sensing was used to extract spatial characteristics of the farm and LAI growth limits. In this study, pasture height was assumed to be $10-16 \mathrm{~cm}$ (corresponding to $\mathrm{LAI} \in[2,4])$, the minimum grass height to start mowing was $24 \mathrm{~cm}(\mathrm{LAI}=6)$ and grass height after mowing was $6 \mathrm{~cm}$ $(\mathrm{LAI}=1)$. Simulations began on 1 March (with a grass height of $8 \mathrm{~cm}$, i.e., LAI $=1.5$ ) and ran for 250 simulated days.
Four validation farms were used in this study, two using conventional practices $(\mathrm{C} 1$ and $\mathrm{C} 2)$ and two using organic practices (O1 and $\mathrm{O} 2)$ (Table 1). Since PaturMata generated 10 different farms for each configuration, mean predictions were used for validation.

\section{Results and discussion}

In this section, we first evaluate the consistency of PaturMata's predictions: $N_{\mathrm{G}}, N_{\mathrm{M}}, T_{\mathrm{G}}, T_{\mathrm{M}}, T_{\mathrm{MM}}, \mathrm{GG}, \mathrm{MM}, \mathrm{GM}$, and MG. We then illustrate PaturMata's ability to simulate grassland growth under various climatic conditions.

\subsection{Quantitative evaluation of PaturMata}

PaturMata generated consistent simulations that corresponded to expert knowledge. Grazing and mowing events and periods of the 10 simulations were predicted for each of the four farms, averaged by farm, and then compared to observed data (Table 2). PaturMata predictions lay within expected ranges. Comparing conventional and organic practices, it is interesting that grass was directly fed to cattle, since organic farms had more grazing periods. This is also confirmed by the mean number of mowing events, which equaled 1.0 for all 20 organic farm simulations. For conventional farms, some simulations generated more than one mowing event, and some fields were only mowed. For organic farms, grazing events occur more frequently, and grassland was never only mowed. Finally, the number of days between two management practices was usually larger for organic farms because their grass grew more slowly.

Dynamics of grass height (Fig. 2) confirmed that organic farms had no mowing-only grasslands (mowing was always followed by grazing). All values appeared consistent. Grass used for mowing grew to a height of $\approx 25 \mathrm{~cm}$, while the height of grazed grass varied from $5-15 \mathrm{~cm}$. Mowing periods were consistently around days-of-year 140 (May) and 300 (October).

Comparison of these predictions to observed data demonstrate PaturMata's ability to simulate consistent scenarios of

Table 1 Physical characteristics of the two conventional farms (C1 and $\mathrm{C} 2)$ and two organic farms (O1 and $\mathrm{O} 2)$ used for validation

\begin{tabular}{|c|c|c|c|c|c|c|c|}
\hline & $\begin{array}{l}\text { Surface } \\
\text { area (ha) }\end{array}$ & $\begin{array}{l}\mathrm{Nb}^{*} \\
\text { fields }\end{array}$ & $\mathrm{LSU}^{* *}$ & $\begin{array}{l}\% \text { Surface } \\
\text { close dist. }\end{array}$ & $\begin{array}{l}\% \text { Surface } \\
\text { medium dist. }\end{array}$ & $\begin{array}{l}\% \text { Surface } \\
\text { far dist. }\end{array}$ & $\begin{array}{l}\text { Fertilization } \\
\text { (kg N ha an) }\end{array}$ \\
\hline $\mathrm{C} 1$ & 70 & 24 & 120 & 59 & 25 & 16 & {$[120,180]$} \\
\hline $\mathrm{C} 2$ & 55 & 30 & 100 & 41 & 47 & 12 & {$[120,180]$} \\
\hline $\mathrm{O} 1$ & 70 & 28 & 90 & 35 & 37 & 28 & 0 \\
\hline $\mathrm{O} 2$ & 95 & 24 & 160 & 44 & 28 & 28 & 0 \\
\hline
\end{tabular}

*number of fields; ** livestock units 
Table 2 Mean characteristics predicted by PaturMata and (last line) observed for conventional ( $\mathrm{C} 1$ and $\mathrm{C} 2)$ and organic $(\mathrm{O} 1$ and $\mathrm{O} 2)$ farms

\begin{tabular}{|c|c|c|c|c|c|c|c|c|c|}
\hline & \multicolumn{2}{|c|}{ \# Grazing or mowing events } & \multicolumn{3}{|c|}{ Practices $(\%)$} & \multicolumn{4}{|c|}{$N$ Days between events } \\
\hline & $N_{\mathrm{G}}$ & $N_{\mathrm{M}}$ & $T_{\mathrm{G}}$ & $T_{\mathrm{M}}$ & $T_{\mathrm{MM}}$ & GG & MM & GM & MG \\
\hline $\mathrm{C} 1$ & 3.5 & 1.1 & 45.5 & 7.5 & 47 & 43 & 99 & 48 & 41 \\
\hline $\mathrm{C} 2$ & 3.7 & 1.2 & 44 & 7 & 49 & 42 & 70 & 79 & 46 \\
\hline $\mathrm{O} 1$ & 4.1 & 1.0 & 79 & 0 & 21 & 43 & - & 117 & 49 \\
\hline $\mathrm{O} 2$ & 3.8 & 1.0 & 75 & 0 & 25 & 45 & - & 68 & 47 \\
\hline $\begin{array}{l}\text { C Exp. } \\
\text { Out. }\end{array}$ & $\in[3,5]$ & $\leqslant 2$ & - & - & - & $\in[30,40]$ & $\geqslant 50$ & $\geqslant 50$ & $\in[40,50]$ \\
\hline O Exp. & $\in[3,6]$ & $\leqslant 1$ & - & - & - & $\in[35,45]$ & - & $\geqslant 70$ & $\in[50,60]$ \\
\hline
\end{tabular}

$\overline{N_{G} \text { mean number of grazing periods per field each year, } N_{M} \text { mean number of mowing events per field each year; grassland management strategies }}$ for each field: $T_{G}$ grazing, $T_{M}$ mowing, $T_{M M}$ mixed; $G G$ number of days between two grazing events; $M M$ number of days between two mowing events $G M$ number of days between two successive grazing and mowing events; $M G$ number of days between two successive mowing and grazing events

farming systems once initial conditions (farm characteristics, climatic conditions, etc.) are set (Table 1). In the next section, we use PaturMata to generate and analyze changes in farming systems when climatic conditions change.

\subsection{Using PaturMata to evaluate grassland states under climate change}

We then simulated the same farms with PaturMata using modified climate data. Climate variables, mostly related to dryness and temperature, were either favorable, unfavorable, and very unfavorable for grassland growth. For example, when simulations are done under favorable conditions, the climatic situations encourage grass growth (no heat wave, no flooding, etc.). At the opposite, unfavorable or very unfavorable conditions mean either dryness or heat/cold wave, preventing from a convenient grass growth. This results in seven scenarios:

- Scenario SO, favorable climate throughout the simulation;
Fig. 2 Predicted dynamics of grass height by management type (grazing only, mowing only, mixed grazing and mowing) for the two conventional farms $(\mathrm{C} 1$ and $\mathrm{C} 2)$ and two organic farms (O1 and O2) studied. Conventional practices can generate several cuts per year (mowing), unlike organic practices, which generate no more than one cut per year followed by grazing events (mixed)
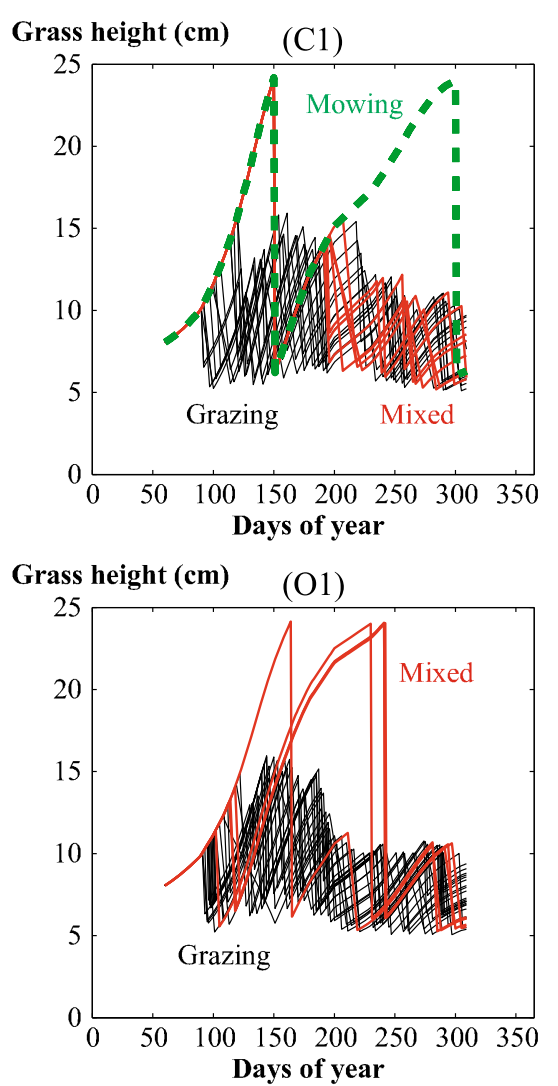
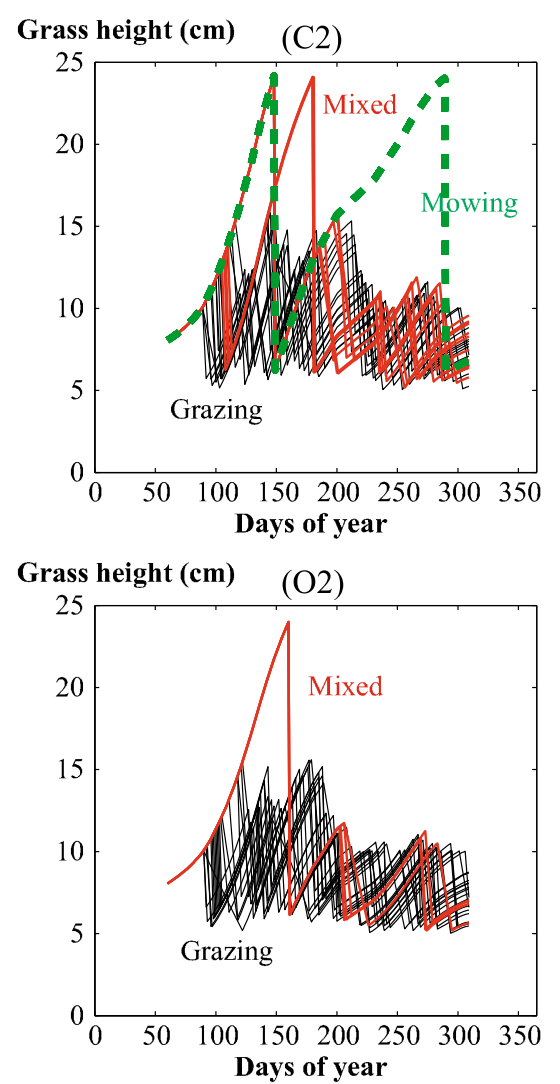
Fig. 3 PaturMata predictions of a the number of grazing periods and b) mean grass consumption vs. mean conserved-forage consumption under a variety of climatic conditions. The more unfavorable the climatic conditions (S0 to S6), the less grass is produced and consumed (solid black and blue lines, respectively) and the more conserved forage is required (dashed red line)

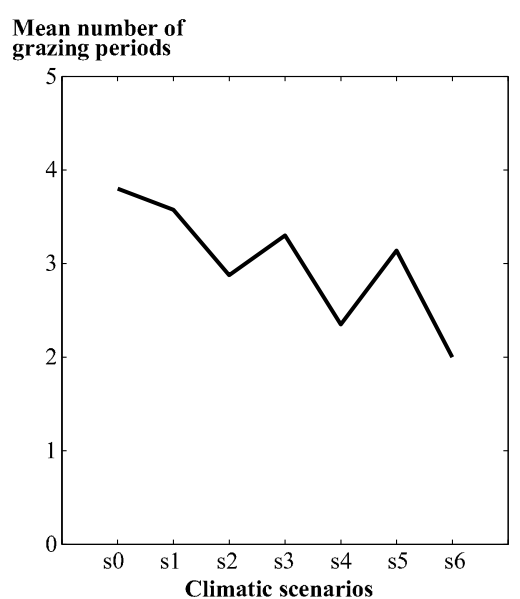

- Scenario S1, unfavorable climate for 40 days starting at the end of March;

- Scenario S2, very unfavorable climate for 40 days starting at the end of March;

- Scenario S3, unfavorable climate during July and August;

- Scenario S4, very unfavorable climate during July and August;

- Scenario S5, unfavorable climate for 40 days starting at the end of March and during July and August;

- Scenario S6, very unfavorable climate for 40 days starting at the end of March and during July and August.

As expected, as climatic conditions worsened, the mean number of predicted grazing periods decreased (Fig. 3a). The magnitude of unfavorable climatic conditions (e.g., S1 vs. S2) had more influence than their frequency (e.g., S1 vs. S5). The quantity of external (conserved) grass required to feed cattle increased as grass growth decreased due to climatic conditions (Fig. 3b). These results seem logical and illustrate PaturMata's ability to simulate sound scenarios that can be used in other forecasting studies of grasslands.

\section{Conclusion}

We introduced a powerful model that can simulate consistent scenarios of grassland management. PaturMata relies on hierarchical discrete-event modeling that is expressed by a set of timed automata. The performance of modelchecking tools accelerates simulations and scenario comparisons. PaturMata predictions were validated with data from on-site surveys and remote sensing. Results revealed PaturMata's ability to predict reliable and sound time series of vegetation characteristics that are consistent with observations from conventional and organic farms. This kind of tool is valuable for generating forecasting scenarios, including those related to climate change. We illustrated this ability by simulating unfavorable climatic conditions and showed that the model predicted well dynamics of grass stocks, fodder requirements, etc., PaturMata may be useful for evaluating consequences of current environmental changes on grasslands.

Acknowledgments We thank Philippe Faverdin for discussions and help with Patur'IN, Françoise Vertès for fruitful discussions and precious help with grasslands and Christine Largouët for her expertise in timed automata for environmental systems.

\section{References}

Alur R, Dill DL (1994) A theory of timed automata. Theor Comput Sci 126(2):183-235. doi:10.1016/0304-3975(94)90010-8

Arrouays D, Deslais W, Badeau V (2001) The carbon content of topsoil and its geographical distribution in france. Soil Use Manag 17(1):7-11

Batáry P, Báldi A, Erdõs S (2007) Grassland versus non-grassland bird abundance and diversity, in managed grasslands: local, landscape and regional scale effects. Biodivers Conserv 16:871-881

Cros Mj, Garcia F, Martin-Clouaire R (1999) SEPATOU: a decision support system for the management of rotational grazing in a dairy production. In: Proceedings of 2 nd European Conference on Information Technology in Agriculture, in: Schiefer G., Helbig, p 549-557

Delaby L, Peyraud J, Faverdin P (2001) Patur'IN: le paturage des vaches laitieres assisté par ordinateur. Fourrages 167(2):385-398

Dusseux P, Corpetti T, Hubert-Moy L (2013) Temporal kernels for the identification of grassland management using high spatial resolution remote sensing time series. In: IEEE Int. Geoscience and Remote Sensing Symp., IGARSS '13, Melbourne, Australia, pp. $3258-3260$

Dusseux P, Corpetti T, Hubert-Moy L, Corgne S (2014) Combined use of multi-temporal optical and radar satellite image for grassland monitoring. Remote Sens 6:6163-6182. doi:10.3390/rs6076163

Friedl MA, Michaelsen J, Davis FW, Walker H, Schimel DS (1994) Estimating grassland biomass and leaf area index using ground and satellite data. Int J Remote Sens 15:1401-1420

Guo X, Price KP, Stiles JM (2000) Biophysical and spectral characteristics of cool- and warm-season grasslands under three land management practices in eastern kansas. Nat Resour Res 9(4):321-331 
Howden SM, Soussana JF, Tubiello FN, Chhetri N, Dunlop M, Meinke H (2007) Adapting agriculture to climate change. Proc Natl Acad Sci 104(50):19,691-19,696. doi:10.1073/pnas. 0701890104. http://www.pnas.org/content/104/50/19691, PMID: 18077402

Jacquemoud S, Verhoef W, Baret F, Bacour C, Zarco-Tejada P, Asner G, François C, Ustin S (2009) PROSPECT + SAIL models: A review of use for vegetation characterization. Remote Sens Environ 113(Supplement 1):S56-S66

Lobell DB, Field CB (2007) Global scale climate-crop yield relationships and the impacts of recent warming. Environ Res Lett 2(1):014,002

Martin G, Martin-Clouaire R, Rellier JP, Duru M (2011) A simulation framework for the design of grassland-based beef-cattle farm. Environ Model Softw 26(4):371-385. doi:10.1016/j.envsoft.2010. 10.002

Martin G, Martin-Clouaire R, Duru M (2013) Farming system design to feed the changing world. A review. Agron Sustain Dev 33(1):131-149. doi:10.1007/s13593-011-0075-4

Ménesguen A, Piriou JY (1995) Nitrogen loadings and macroalgal (Ulva sp.) mass accumulation in Brittany (France). Ophelia 42(1):227-237. doi:10.1080/00785326.1995.10431506

Moreau P, Ruiz L, Mabon F, Raimbault T, Durand P, Delaby L, Devienne S, Vertès F (2012) Reconciling technical, economic and environmental efficiency of farming systems in vulnerable areas. Agric Ecosyst Environ 147:89-99

Moreau P, Ruiz L, Vertès F, Baratte C, Delaby L, Faverdin P, GascuelOdoux C, Piquemal B, Ramat E, Salmon-Monviola J, Durand P (2013) CASIMOD'N: an agro-hydrological distributed model of catchment-scale nitrogen dynamics integrating farming system decisions. Agric Syst 118:41-51

Peeters A (2009) Importance, evolution, environmental impact and future challenges of grasslands and grassland-based systems in Europe. Grassl Sci 55(3):113-125

Poudevigne I, Alard D (1997) Landscape and agricultural patterns in rural areas: a case study in the Brionne basin, Normandy, France. J Environ Manag 50(4)

Rondeaux G, Steven M, Baret F (1996) Optimization of soil-adjusted vegetation indices. Remote Sens Environ 55(2):95-107

Soussana JF, Lüscher A (2007) Temperate grasslands and global atmospheric change: a review. Grass Forage Sci 62(2):127-134.

Tubiello FN, Soussana JF, Howden SM (2007) Crop and pasture response to climate change. Proc Natl Acad Sci 104(50):19,68619,690. doi:10.1073/pnas.0701728104. http://www.pnas.org/ content/104/50/19686, PMID: 18077401

Vertès F, Hatch D, Velthof G, Taube F, Laurent F, Loiseau P, Recous S (2007) Short-term and cumulative effects of grassland cultivation on nitrogen and carbon cycling in ley-arable rotations. In: Permanent and temporary grassland: Plant, Environment and Economy, 14th symposium of the European Grassland Federation Ghent, A. de Vliegler and L. Carlier, (eds.), Grassland Science in Europe, pp 227-246

Zhang C, Guo X (2008) Monitoring northern mixed prairie health using broadband satellite imagery. Int J Remote Sens 29(8):22572271

Zhao Y (2014) Modélisation qualitative des agro-écosystèmes et aide à leur gestion par utilisation d'outils de model-checking. $\mathrm{PhD}$ thesis, Université Rennes 1. http://tel.archives-ouvertes.fr/tel-00933443 